\title{
Is there a role for Educational Psychologists in facilitating managed moves?
}

\section{Christopher Bagley and Susan Hallam}

\begin{abstract}
The current research aimed to explore the extent to which school professionals and Local Authority staff perceived that there was a role for Educational Psychologists in the processes involved in implementing, monitoring and offering support to young people for whom a managed move was being arranged. The study was conducted in one English Local Authority where eleven school staff and five Local Authority staff were interviewed using a thematic analysis methodology. The emerging themes were: lack of role clarity; variability between schools; reactive in relation to crisis; capacity; and possibilities for further involvement including transition, preventative work and accurate assessment of needs.
\end{abstract}

\section{Keywords}

Managed moves, exclusion, Educational Psychology, Local Authority, social constructionist, systems thinking.

\section{Introduction}

Educational Psychologists (EPs) 'have a central role in the statutory assessment and statementing procedures for children with special educational needs (SEN).Employed by local authorities, they also contribute to behaviour-support work and early intervention'(Department for Education (DfE), 2011b).Although this definition conceptualises the role of EPs as practitioners working predominately with young people with Special Educational Needs, EPs tend to define themselves in much broader terms.

According to Cameron (2006), EP work should: adopt a psychological perspective on the nature of human problems, uncover mediating variables which may provide an explanation of why certain events may be related, unravel problem dimensions using models which can be used to 
understand complex human data, provide a simple but useful map of the interaction between people factors and aspects of their living / learning environments and promote innovative concepts or big ideas which are underpinned by psychological research evidence, i.e. evidence-based strategies.

In recent decades, there has been a recognition that EPs should work systemically, for instance drawing on the work of Bronfenbrenner (1979) whose eco-systemic model sets out how human beings operate within a complex, multi-layered system, where individuals and groups of people impact upon others. Most EP training espouses a social constructionist perspective (Burr, 2005) which assumes that social discourse shapes the acquisition of knowledge and conception of reality. This contrasts with what Stobie(2002) describes as the 'defunct traditional model', where 'problems' are viewed as within-childandEPs are seen as assessors of need and gatekeepers to resources. There has been a move away from this model towards a reconciliation of the pragmatic and the scientific through the conceptualisation of EPs role as that of "scientist-practitioner" (Lane \& Corrie, 2006).

Farrell, Woods, Lewis, Rooney, Squires and O'Connor (2006) argue that one role for EPs is to bring coherence to work across agencies. This is referred to as 'bridging', and can involve coordinating delivery of service across groups of professionals from divergent backgrounds. EP training providers encourage the development of consultation skills and working models in line with a systemic, interactionist, solution-focussed approach (Wagner, 2000), which often incorporates solution-focussed methods to elicit strategies and possibilities for positive change. It is assumed that clients are endowed with the resources to exact change; a move away from the deficit model of working, where EPs are conceptualised as experts. Despite this, many service users have highlighted the role of EPs as experts as the most valued element of their work (Ashton \& Roberts, 2006).

These contrasting conceptualisations may contribute to what has been described as an 'identity crisis' for EPs (Cameron, 2006) where there is concern about the 'distinctiveness' of the role, and difficulty in forming a stable identity (Cameron, 2006; Farrell et al., 2006; Love, 2009). EPs have to justify their role and there is need for the profession to be seen to be relevant, as described byGersch(2009), who also argues that there is a need to anticipate what role EPs may have in the future and the nature of the work they may undertake. One possibility is in relation to exclusions, supporting young people at risk of exclusion and interventions designed to prevent them. 
Daniels, Cole, Sellman, Sutton, Visser and Bedward(2003) point out that government guidance on exclusion suggests that head-teachers should consider a multitude of factors when deciding whether or not to exclude. These include the young person's previous record, the frequency and severity of behaviour precipitating exclusion, and whether other agencies have been involved, including Educational Psychologists. They state that these considerations are inadequately accounted for in many cases. They stress a need for greater EP involvement in exclusion processes. Parson (2009) noted that in the low excluding Local Authorities he studied, a young person could not be excluded without the input of an EP, who might provide insights as to alternative ways of approaching a young person and tailoring their learning environment to their individual needs. These observations suggest that EPs might have a role to play in relation to managed moves which constitute an alternative to permanent exclusion.

Managed moves have been defined in the guidance provided by the Department for Children, Families and Schools (DCFS) (2008) as enabling the pupil to have a fresh start at a new school, with the full cooperation of all parties involved, including parents, governors and the Local Authority. Currently, Local Authorities are tasked with instigating managed moves using whatever processes they deem to be appropriate. The number of managed moves is not known at present. There are no standardised processes or regulatory systems in place to guide their administration or record their prevalence nationally (Osler, Watling, Busher, Cole and White, 2001), although practitioners and researchers have produced guidance to support the process in addition to that provided by the DCSF (Children and Young People's Directorate of Somerset County Council, 2008; Office of the Children's Commissioner, 2013b; Abdelnoor, 2007; Vincent, Harris, Thomson and Toalster, 2007). There is broad agreement that a managed move must constitute a fresh start for the young person; be undertaken with the full cooperation of all parties involved, including parents, governors and the Local Authority; with effective collaboration and communication between initial and receiving schools; taking account of the child's needs and his/her views in the decision making process; andwith a support package in place. Vincent et al (2007) in their evaluation identified the main characteristics of a successful managed move as a phased integration over a number of weeks, shared control across a number of key stakeholders and young people being consulted. The young people themselves valued relational factors, in particular, feeling ... 'genuinely cared about, wanted, listened to and supported' (pg 290). The success of the initiative was partially reliant on the inclusivity of the new school, and the capacity of the present and new schools to cooperate and coordinate actions and be flexible. The need for 
schools to respond pro-actively, creatively and flexibly to individual needs was advocated by the young people, alongside being given focused support, not just during integration, but long term. When these conditions were present, the young people reported the development of new attitudes and motivation and a more positive view of themselves and their schools.

Abdelnoor's(2007) vision of a managed move incorporates a process of restorative justice, or reparation by the young person to 'make amends' for their behaviour. Subsequently, having acted out their punishment and ensured that the young person has been made accountable for their actions before the school, a managed move can then occur on a 'voluntary' basis. This would be coordinated by a trained 'facilitator', who would act as a neutral body in brokering the move between schools, showing unconditional positive regard for all stakeholders. Abdelnoor's definition of the 'facilitator' role in brokering managed moves aligns very closely with the working model espoused by many EP training providers. Abdelnoor suggests that managed move planning and execution should be characterised by solution-focussed thinking, flexible negotiation and planning across multi-agencies. The facilitator position is described as being one of 'minimal power and maximum influence'. The facilitator must have good relational skills, be able to work effectively within an emotionally charged environment, have a 'unifying perspective' and good psychological awareness, and understand the value of free reciprocal agreements. This role might be undertaken by Educational Psychologists. The aim of the research reported here is to explore with Local Authority and school staff whether they perceive that Educational Psychologists might have a role in supporting managed moves.

\section{Methodology}

The research was conducted in one relatively prosperous Local Authority in the South East of England. Interviews were undertaken with Local Authority personnel and school staff. It was important to establish the perceptions of those engaged with the management and implementation of the process and its outcomes in schools and Local Authorities. School staff because they were engaged in the day to day implementation of managed moves and the assessment of their outcomes and Local Authority officers as they had overall responsibility for ensuring that the young person is attending school and appropriately engaged in education. 
All participants were assured that their identities would remain confidential. Interviews with Local Authority officers were conducted at the borough head office while school staffwere interviewed at schools. Interviews lasted between 12 and 42 minutes. Eleven school staff were interviewed. Their professional roles varied and included Head-teachers, SENCOs and Inclusion Officers. All had been involved in the managed move process in a bi-directional fashion. They all had experience of hosting a young person on a managed move and requesting or enacting a managed move. Five Local Authority officers were interviewed, including: the officers responsible for exclusion and managed moves in the borough, an Education Welfare Officer (EWO), the Head of the borough's multi-agency team for Children Looked After.Two Educational Psychologists currentlyworking within the secondary schools in the research borough were also interviewed. The interviews were conducted as part of Educational Psychology Service Research and formed part of a broader study in which young people and parents were also interviewed as to their experience of managed moves. It is however recognised that the sample size is small and this is certainly a limitation of the current study.

In the interviews participants were askedtwo questions:

- 'What role do Educational Psychologists have in managed moves?'

- 'How do you feel that Educational Psychologists could assist with managed moves?'

The analysis was data-driven and themes were allowed to emerge from the data (Patton, 1990). Braun and Clarke's (2006) guidelines were followed. These included familiarisation with the data through reading transcripts a number of times, generating initial codes, searching for themes and reviewing, defining and naming themes. In coding participant responses, each mention of a specific issue was coded individually. For instance, where a member of school staff made twocomments in relation to preventative work, this was coded twice. It was felt that this would present a picture of the perceived importance of specific issues, which would not be captured if the data were coded on a person by person basis. Although the research was essentially qualitative, the numbers of times a particular theme was mentioned gave an indication of the extent to which similar views were held by participants from different groups. The quantification of qualitative responses is now well recognised for this purpose supported by the introduction of qualitative data analysis packages, e.g. NVivo. (Bazeley \& Jackson, 2013). Although such a package was not used in this research the process was undertaken to enhance understanding of the different perspectives and the strength with which perceptions were shared. A judgement was made in relation to coding the number of times a participant mentioned a specific issue to ensure that the data were not 
invalidly skewed. For example, when a Headteacher mentioned 'capacity issues' on three occasions in response to question one, this was coded as one mention. If this was mentioned again in response to question two, this was recorded again, once.

\section{Results}

A range of themes emerged from the analysis including: lack of role clarity; variability between schools; reactive in relation to crisis; capacity; and possibilities for further involvement (transition, early preventative work, assessment of needs).

\section{Lack of role clarity}

This was the mentioned eight times by school staff and five times by Local Authority officers. School staff were often unclear as to the extent to which Educational Psychologists currently had a role in facilitating managed moves. A number of school staff said 'I don't know', as did Local Authority officers: 'I am not conscious that they have a specific role...' A number of school staff admitted that they were under-informed as to what EPs could contribute to the process: 'this sounds ridiculous I should know but I don't really know what EPs do'. Another member of school staff said: 'I don't know really is the answer to the question... if I don't know how they could help then maybe I need more information about how they could help'.

Other school staff suggested specific, narrow roles that EPs currently undertake, such as working with those with 'low literacy', or 'to assess their ability educationally wise not their psychological side... and behaviour issues unless it is ADHD...' One Local Authority officer indicated that,EPs are 'associated mainly with learning difficulties' and often, therefore are not aligned with the managed move process, within which issues are generally conceived as arising from 'behaviour' concerns. Neither school staff nor Local Authority officers highlighted a specific role for EPs. The data suggested that schools, at present, do not use EPs to assist with managed moves in a systematic way and, in manycases, were unaware of how they might do so.

\section{Variability between schools}

Six comments were made by school staff and seven by LA officers in relation to the discrepancy in EP involvement across different schools: As one LA officer put it: 'it totally varies', although 
the school EP is 'very rarely involved' in the actual managed move. Similarly, a member of school staff reported that 'it depends on the school'. A number of school staff indicated that EPs would be involved only if they had previously had some interaction with the young person. One participant explained that if an EP is already involved with that family... then it would continue over to here...' Another felt that EP involvement 'depends on the EP that you happen to be working with'.

Overall, the data suggested that EPs were rarely, if ever, brought in specifically to facilitate a managed move. There were, however, reports that EPs might be brought in to 'add weight' to a school's picture in relation to a young person. One Local Authority officer raised this issue also, in arguing that sometimes EPs 'are brought in as a tick box exercise' so that schools can show they have attempted to intervene where a young person is at risk. In this context, it was interesting to note that three Local Authority officers felt that EPs should have a 'statutory role' in the managed move process supporting individual young people and their families.

\section{Reactive in relation to crisis}

One member of school staff and three Local Authority officers made reference to EP involvement taking place in reaction to a young person reaching crisis point. The member of school staff suggested that where a managed move was failing ... 'then asking for an urgent EP assessment would probably be one of the things you would consider because there's clearly quite a lot of issues that need to be uncovered'. Again, Local Authority officers referred to this issue more often, two feeling that EPs should have 'a statutory role in facilitating moves'. Another said: 'it is about ensuring that support goes into place at an early point but you know again often the alarm bell only gets pulled once the fire has started and it is too late...'

Concerns were raised by Local Authority officers in relation to schools capacity to be proactive, rather than reactive, within a school system where 'the pastoral side is completely split from the learning / SENCO side and the two sides don't communicate'. Hence, when a young person exhibits behavioural difficulties, they 'may not be considered to have learning needs' and will therefore go 'down route B (pastoral) and that is not the side connected with EPs very much'.

\section{Capacity}


School staff made four comments regarding EP capacity, while only one Local Authority officer commented on this. Frustrations were raised by school staff with regard to the limited time allocations that EPs have within schools: for instance one indicated that it would be better 'If they were here a bit more'. Another referred to this as the 'the age old capacity question. There is only a finite resource and inevitably most schools have got, you know, a stack of people waiting'.

Frustration was expressed by a number of school staff regarding the time it took for EPs to input in challenging cases. One argued that, while an EP report may be useful once a managed move is suggested; 'it has to be done quickly, the problem is, these things take such a long time'.

There were a number of comments from school staff relating to the high cost of EPs and assertions that if their services were 'cheaper' and there was 'more EP time available', this 'would obviously help'.

\section{Further involvement}

There were a number of key areas where school and Local Authority staff felt that EPs might have greater involvement within managed moves. The main areas that emerged included: transition, preventative work and assessment of needs.

Transition:Five comments were made by school staff and four by Local Authority officers in relation to EPs working to facilitate transitions within a managed move framework. One member of school staff referred to the potentially 'hostile environment' that young people may face in making transitions and suggested that EPs might 'reinforce what we are trying to do in supporting those young people in establishing what set of social interaction skills they are lacking and what resiliencies they are lacking emotionally'. A similar assertion was made by a Local Authority officer, who noted that EPs 'could help to plan inclusive programmes for kids with families and schools alongside the school and help facilitate transition'.

One LA officer emphasised the fact that EPs tend to use systemic thinking as a working model and this may assist in facilitating a well-planned transition: 'EPs tend to think quite systemically and might... help the transition through conversations with other teaching staff at a school a kids is moving to'. 
Two members of school staff stated that, in their experience, most young people who experience a managed move will have had some form of EP involvement in the past. However,

... 'regarding the transition process, assisting the family in coping with the move etc, EPs aren't involved that often in my experience. Maybe that's something that needs to change'.

Another member of school staff concluded that 'maybe that's a gap'.

Preventative work:Five members of school staff and four Local Authority officers made reference to preventative work as a potential role for EPs. One member of school staff said: 'we needed to get involvement earlier ... they would certainly jump up our list of somebody who needs some input'. Another member of school staff recognised the importance of gaining an 'early diagnosis within the host school'. This issue was raised by a number of other school staff who felt that EP involvement, prior to a young person moving would give the host school greater knowledge of their individual needs and therefore, opportunity to competently put measures in place to facilitate the process. One commented:

... 'it feels to me that (EPS) should be involved before the managed move is set up actually because something is not right and if you were involved before, it helps smooth the transfer'.

Another member of school staff highlighted the potentially 'deep rooted issues' that some young people face, going on to say that EPs 'could play a huge role actually. The managed moves whatever the issues are there are ... Teachers are stuck'. Other members of school staff also proposed that they sometimes lacked the requisite skills to identify needs and implement learning programmes, particularly in complex cases and this could be a role for EPs, working preventatively.

There was general agreement amongst Local Authority officers that EPs 'might be able to work preventatively to stop the need for a managed move'. They acknowledged the issue that 'there probably isn't enough of a role for EP's...' and suggested that 'early intervention is more cost effective 'and might ... 'stop the potential for a statutory assessment'.

Assessment of needs:Two members of school staff and four Local Authority officers suggested that EPs should take a greater role in assessing young people's needs. There was some 
acknowledgment across both sub-groups that this would not need to take place in every instance. As stated by one member of school staff:

'I don't know whether every managed move needs EP involvement or not... we ought to discuss everyone with an EP in case there is some involvement for them. That's probably something we don't do very well at the moment'.

Further, participants suggested that EPs could have a role in assessing young people prior to them moving schools. Professionals made reference to the potential for EPs to establish educational, social and emotional needs effectively, to determine whether a managed move would be an appropriate intervention and if so, what strategies would best support a young person in doing so. There was a general view across school staff that EPs have the capacity to perform more rounded, holistic assessment when compared with teachers and schools. One member of school staff said:

'At the moment we just look at their educational side... if we could get a look into the behavioural aspects that would help...'

Local Authority officers also commented on the validity of schools using EP time to ensure that young people's views are accurately assessed. As suggested by one participant, EPs could work to ... 'see if there are any other issues and if the managed move doesn't work is it maybe because the school haven't looked deeply'.

\section{Overview}

Table 1 shows the number of mentions made by each sub-group in relation to the sub-themes described above.No generalisable conclusions can be drawn from the number of responses of each group as the sample is too small. There seemed to be agreement between school staff and Local Authority officers that there is a lack of clarity about the role of EPs particularly in relation to managed moves. There was also concurrence across sub-groups as to the variability of EP involvement across schools. School staff were much more aware of capacity issues than Local Authority officers. Members of both groups suggested that EPs could play an important and increased role in managed moves.

Table 1: Summary of super-ordinate theme 6: EP role (should go here) 


\section{Discussion}

There are limitations to this research in that it was carried out in one Local Authority with a small sample.However, some useful conclusions can be drawn.Furthermore, it would have been useful to know the extent to which managed moves are currently successful. It was not possibleto establish this as the research borough, at the time of data collection, did not adequately record this information. Some managed moves were logged with the Local Authority, others were not, thus making it impossible to gain an accurate picture of the number and success rate. Understanding the extent to which managed moves fail or succeed would provide a richer picture as to the potential value of EP intervention; future research should aim to rectify this.

School staff and Local Authority officers were often unsure as to the current role of EPs. Despite considerable evidence of the extensive skill base of EPs (Farrell et al., 2006; Love, 2009), the perception of stakeholders interviewed for this study tends to posit EPs as associated with 'learning' and not 'behaviour'. This is not a new finding and reflects on-going difficulties facing the profession in establishing value and demonstrating effectiveness in an educational climate where individual schools are taking increasing control over their budgets (Gersch, 2009).

The extent to which EPs are involved in managed moves is currently dependent on the practice of individual schools. It is likely that variations across context are partially dictated by the extent to which school staff know what EPs can offer. In a context where EP work is increasingly moving towards a "buy-back" / traded services model, it is necessary for EPs to demonstrate the value of their contribution to individual schools. It may be the responsibility of individual EPs to explain their role to schools, families and Local Authority officers who work in different services. It is possible that, at present, EPs are rarely involved in managed moves because school staff and Local Authority officers are unaware of the impact that they could make. Tensions exist within traded services as to how EP involvement would be funded. It would certainly be helpful for LAs and / or individual schools to have shared protocols and agreements as to how this issue would be resolved. Those who were interviewed suggest it may be most effective for the EP at the starter school to have involvement, as they are likely to have greater knowledge of the young person and what would work best in support of their transition.

EP's skills and professional training is ideally suited to facilitating managed moves, as highlighted by Cameron (2006). The role of managed move facilitator, as postulated by Abdelnoor (2007) 
should possess good relational skills, be able to work effectively within an emotionally charged environment, have a 'unifying perspective' and good psychological awareness and use solutionfocused thinking.It is not suggested that EPs should facilitate via promoting or advocating managed moves. However, when a managed move is initiated, EPs could have a role in ensuring the process takes place in a way that genuinely meets a young person's needs. In some cases it may not be necessary for an EP to be involved, for example when a young person's psychological, social and emotional needs have been rigorously identified and both starter and host school have a clear picture as to how to support their transition. In contrast, when there are unidentified needs in any of these areas, EPs are ideally placed to provide consultation and assessment with the aim of providing a clearer picture in the best interests of the young person. EPs are also well placed to support families in coping with the transition and managing the challenges presented.

School staff and Local Authority officers proposed that EPs could work preventatively, through 'diagnosing' needs, to build an accurate picture of a young person's needs prior to a managed move and help to avoid permanent exclusion. Given the salience of producing accurate assessments of young people,EP involvement may be paramount in facilitating successful managed moves. Some Local Authority officers suggested that EPs might take a statutory role in regulating the managed moves process. This is unrealistic, given the government's drive to raise academic standards, at the expense of other areas of development. However, it should be possible for EPs to encourage the organisationof multi-professional meetings at schools, to signpost any young people who might benefit from a managed move.

Within such meetings, EPs may have an important role in challenging negative narratives around young people.In some cases, myths may have developed which will shape the way that school staff and peers interact with a specific young person. Schools may perceive problems as being 'within-child'. There is clearly a role for EPs to support school staff and other professionals to reconceptualise the nature of the difficulties faced, including the extent to which external factors are impinging upon a child. EPs can take a systemic view (Bronfenbrenner, 1977, 1979, 1990, 1994) to promote a meta-analysis of the issues at hand. Consultation based on Wagner's (2000) model is a useful platform from which to do so. Furthermore, social constructionist epistemology (Burr, 2003) could have a role in un-picking the way that discourses have evolved in relation to one or more young people. EPs are uniquely well placed to operate within this framework. This would offer opportunities for preventative work and signpost young people who may need further assessment to establish needs. 
Some Local Authority officers suggested that EP work within managed move cases was often reactive and took place too late. A contributory factor in some secondary schools may be the separateness of 'learning' and 'behaviour' support departments, which may not necessarily communicate well with each other. EPs may have a role in challenging systemic problems such as this and must have the confidence and wherewithal to do so. EPs could work to: act preventatively to avoid a managed move being required, through accurate assessment and evidence-based interventions based on knowledge of psychological theory; assist schools in identifying appropriate candidates for managed moves by attending multi-professional meetings; challenge systemic issues and narratives around young people within schools and facilitate transitions / collaborative working through conversations with Local Authority officers and school staff from starter and host provisions.

EPs also possess the requisite skills to elicit young people's views. This is an essential part of transition work, an area where school staff and Local Authority officers saw value in EP involvement. Using PCP and solution-focussed methodologies, EPs have the capacity to assist young people in communicating their views; this is particularly important for young people experiencing managed moves, who may feel alienated from school systems. Allowing space for young people to explore their self-constructs and evaluate what works for them may be crucial in facilitating success. EPs are best placed to achieve this.

In conclusion,EPs have the knowledge and skill base to work closely with schools to plan interventions and ensure that young people's needs are identified. In cases where a young person's needs have not been assessed thoroughly, schools should ensure that this takes place, through consultation with an EP. EP services and individual practitioners must stress the high level of training and expertise that they possess and the potential for impact in cases involving managed moves and exclusion. It is critical that EP practice is not construed as applicable only within a narrow, 'traditional' definition of special educational needs and can be valuable in working with complex young people with social, emotional and behavioural difficulties. In the context of increased commissioning of services and 'buy back', it is increasingly important for EPs to establish themselves as useful within wider contexts, to increase positive impact, uphold moral and ethical values and standards and to ensure the profession maintains its status. EPs should consult with schools to evaluate systems in place to support young people with complex difficulties. In particular, conversations should occur as to teacher-student-family interactions in 
cases where managed moves and exclusions are raised. It is important for EPs to raise the issue of narratives around young people, to explore the validity of the prevailing discourse and accepted "truths" about young people and families. This should ensure that the views of stakeholders are accurate and support inclusion. This will also allow for more preventative work to take place, as difficulties will be recognised early, thus allowing key stakeholders to collaborate in planning interventions to support young people.

\section{Acknowledgements}

Particular thanks to my supervisors, Sue Hallam and Karen Majors for their support throughout this project. Special thanks to the professionals who helped in finding suitable participants and provided excellent advice as to how to pursue this topic.

Also, thanks to the school professionals, Local Authority officers, parents and young people who gave considerable time and much thought to their contributions.

\section{References}

Abdelnoor, A. (2007) Managed Moves. A complete guide to managed moves as an alternative to permanent exclusion. Calouste Gulbenkian Foundation.

Ashton, R. \& Roberts, E. (2006) What is Valuable and Unique about the Educational Psychologist? Educational Psychology in Practice, 22(2), pp 111-223.

Bazeley, P. \& Jackson, K. (2 ${ }^{\text {nd }}$ edition) (2013). Qualitative data analysis with NVivo. Los Angeles: Sage

Braun, V. and Clarke, V. (2006).Using thematic analysis in psychology.Qualitative Research in Psychology, 3, 77-101

Bronfenbrenner, U. (1977) Toward an experimental ecology of human development. American Psychology, 32, pp 515-531. 
Bronfenbrenner, U. (1979). The ecology of human development: experiments by nature and design. Harvard University Press

Bronfenbrenner, U. (1990) The ecology of cognitive development. Zeitschrift fur Socializations Forschun und Erziehungssoziologie (ZSE), 10(2), pp 101-114.

Bronfenbrenner, U. (1994) Ecological models of human development.In International Encyclopedia of Education, 3(2), pp 37-43.

Burr, V. (2003) Social Constructionism. London: Routledge

Cameron, R.J. (2006) Educational Psychology: The distinctive contribution Educational Psychology in Practice, 22(4), pp. 289-304

Children and Young People's Directorate of Somerset County Council (2008) A Somerset Fair Protocol On The Managed Transfer of Pupils Between Schools. Somerset County Council

Daniels, H., Cole, T., Sellman, E., Sutton, J., Visser, J. \&Bedward, J. (2003) Study of young people permanently excluded from school (Research Report No 405) (London, DfES).

DCSF (2008).Improving behaviour and attendance: guidance on exclusion from schools and Pupil Referral Units, DCSF.

DfE (2011b) Educational Psychologists

http://www.education.gov.uk/schools/careers/careeropportunities/a0014613/educationalpsychologists.

Farrell, P., Woods, K., Lewis, S., Rooney, S., Squires, G. and Mike O'Connor, M. (2006) The future of educational psychologists within the new children's services, The Psychologist,19(10).

Gersch, I. (2009) A positive future for educational psychology - if the profession gets it right Educational Psychology in Practice, 25(1), pp 9-19. 
Lane, D.A. and Corrie, S. (2006) The Modern Scientist Practitioner: A Guide to Practice in Psychology. Routledge.

Love, P. (2009) Educational psychologists: the early search for an identity. Educational Psychology in Practice, 25(1), pp 3-8.

Office of the Children's Commissioner (2013b) “Always Someone Else's Problem”. Office of the Children's Commissioner's Report on illegal exclusions. OCC

Osler, A., Watling, R., Busher, H., Cole, T. and White, A. (2001) Reasons for Exclusion from School. Research Report RR244. London: DfES.

Patton, M.Q. (1990) Qualitative Evaluation and Research Methods (2 ${ }^{\text {nd }}$ Ed). Newbury Park, CA: Sage

Parsons, C. (2009) Strategic Alternatives to Exclusion from School. Trentham Books.

Stobie (2002) Processes of 'Change' and 'Continuity' in Educational Psychology - Part 1. Educational Psychology in Practice, 18(3) pp 203-212

Vincent, K., Harris, B., Thomson, P and Toalster, R. (2007) Managed moves: schools collaborating for collective gain. Emotional and Behavioural Difficulties, 12(4), pp. 283-298.

Wagner, P. (2000) Consultation: developing a comprehensive approach to service delivery. Educational Psychology in Practice.16(1), pp 9-18. 
Table 1: Summary of super-ordinate theme 6: EP role

\begin{tabular}{|l|c|c|}
\hline \multirow{2}{*}{ Sub-theme } & \multicolumn{2}{|c|}{ No. of mentions } \\
\cline { 2 - 3 } & School staff & $\begin{array}{c}\text { Local } \\
\text { Authority } \\
\text { Officers }\end{array}$ \\
\hline Lack of role clarity & 8 & 5 \\
\hline Variability between schools & 6 & 7 \\
\hline Reactive in relation to crisis & 1 & 3 \\
\hline Capacity & 4 & 1 \\
\hline Possibilities for further involvement & 5 & 4 \\
- Transition & 5 & 4 \\
- Preventative work & 2 & 4 \\
\hline
\end{tabular}

